\title{
A vibrational spectroscopic study of the anhydrous phosphate mineral sidorenkite $\mathrm{Na}_{3} \mathrm{Mn}\left(\mathrm{PO}_{4}\right)\left(\mathrm{CO}_{3}\right)$
}

\author{
Ray L. Frost ${ }^{\mathrm{a}, *}$, Andrés López ${ }^{\mathrm{a}}$, Ricardo Scholz ${ }^{\mathrm{b}}$, Fernanda Maria Belotti ${ }^{\mathrm{c}}$, Yunfei Xi $^{\mathrm{a}}$

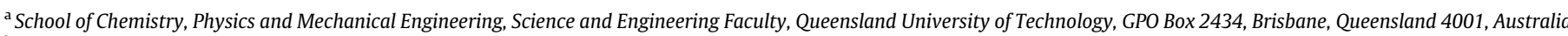 \\ ${ }^{\mathrm{b}}$ Geology Department, School of Mines, Federal University of Ouro Preto, Campus Morro do Cruzeiro, Ouro Preto, MG 35,400-00, Brazil \\ ${ }^{\mathrm{c}}$ Federal University of Itajubá, Campus Itabira, Itabira, MG, Brazil
}

\section{H I G H L I G H T S}

- Sidorenkite $\mathrm{Na}_{3} \mathrm{Mn}\left(\mathrm{PO}_{4}\right)\left(\mathrm{CO}_{3}\right)$ is a phosphate-carbonate of sodium and manganese.

- Such a mineral with two oxyanions lends itself to vibrational spectroscopy.

- Raman bands at $1044 \mathrm{~cm}^{-1}$ and $1074 \mathrm{~cm}^{-1}$ are attributed to the $\mathrm{CO}_{3}^{2}$ stretching modes.

- Raman band at $959 \mathrm{~cm}^{-1}$ and $1012 \mathrm{~cm}^{-1}$ are assigned to the $\mathrm{PO}_{4}^{3-}$ stretching modes.

- Multiple bands supports the concept of a reduction in symmetry of the carbonate anion.

\section{A R T I C L E I N F O}

\section{Article history:}

Received 10 February 2014

Received in revised form 30 June 2014

Accepted 21 August 2014

Available online 10 September 2014

\section{Keywords:}

Sidorenkite

Phosphate

Carbonate

Raman spectroscopy

Infrared spectroscopy
G R A P H I C A L A B S T R A C T

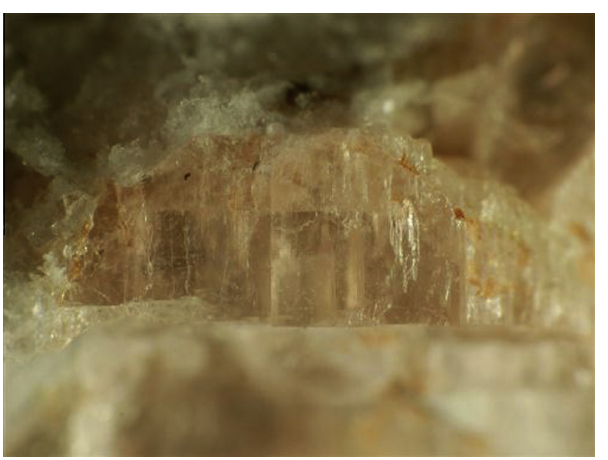

\begin{abstract}
A B S T R A C T
Sidorenkite is a very rare low-temperature hydrothermal mineral, formed very late in the crystallization of hyperagpaitic pegmatites in a differentiated alkalic massif (Mt. Alluaiv, Kola Peninsula, Russia). Sidorenkite $\mathrm{Na}_{3} \mathrm{Mn}\left(\mathrm{PO}_{4}\right)\left(\mathrm{CO}_{3}\right)$ is a phosphate-carbonate of sodium and manganese. Such a formula with two oxyanions lends itself to vibrational spectroscopy. The sharp Raman band at $959 \mathrm{~cm}^{-1}$ and $1012 \mathrm{~cm}^{-1}$ are assigned to the $\mathrm{PO}_{4}^{3-}$ stretching modes, whilst the Raman bands at $1044 \mathrm{~cm}^{-1}$ and $1074 \mathrm{~cm}^{-1}$ are attributed to the $\mathrm{CO}_{3}^{2-}$ stretching modes. It is noted that no Raman bands at around $800 \mathrm{~cm}^{-1}$ for sidorenkite were observed. The infrared spectrum of sidorenkite shows a quite intense band at $868 \mathrm{~cm}^{-1}$ with other resolved component bands at 850 and $862 \mathrm{~cm}^{-1}$. These bands are ascribed to the $\mathrm{CO}_{3}^{2-}$ out-of-plane bend $\left(v_{2}\right)$ bending mode. The series of Raman bands at $622,635,645$ and $704 \mathrm{~cm}^{-1}$ are assigned to the $v_{4}$ phosphate bending modes. The observation of multiple bands supports the concept of a reduction in symmetry of the carbonate anion from $D_{3 h}$ or even $C_{2 \mathrm{v}}$.
\end{abstract}

(c) 2014 Elsevier B.V. All rights reserved.

\section{Introduction}

Sidorenkite $\mathrm{Na}_{3} \mathrm{Mn}\left(\mathrm{PO}_{4}\right)\left(\mathrm{CO}_{3}\right)$ is a phosphate-carbonate of sodium and manganese [1]. The mineral is anhydrous and contains

\footnotetext{
* Corresponding author. Tel.: +61 73138 2407; fax: +61 731381804 .

E-mail address: r.frost@qut.edu.au (R.L. Frost).
}

no hydroxyl units. It is a very rare low-temperature hydrothermal mineral, formed very late in the crystallization of hyperagpaitic pegmatites in a differentiated alkalic massif (Mt. Alluaiv, Kola Peninsula, Russia) [2,3]. The mineral is colorless, pale rose-red to pale pink, with surficial brownish or yellowish tint. The mineral is named in honor of Alexander V. Sidorenko (1917-1982), a Russian mineralogist. 
It is monoclinic, pseudo-orthorhombic with Point Group $2 / m$ and Space Group: $P 21 / m$ or P21. $a=8.997(4) \AA ̊ ., b=6.741(2) \AA$, $c=5.163(2) \AA[4,5]$. The mineral is isostructural with bradleyite and bonshtedtite [6]. Chinh et al. [6] state that a characteristic feature of their structure is edge joining of the $\mathrm{CO}_{3}$-triangles with the $\mathrm{Fe}(\mathrm{Mn}-, \mathrm{Mg}-)$ octahedrons and Na-polygons. The layered character of the structure explains the perfect cleavage shown by the crystals. These minerals form ideal substrates for sodium ion batteries [7]. Other new minerals related to sidorenkite have been established [8-10].

It is important to study the vibrational spectroscopy of sidorenkite as there have been very few studies of this mineral as is evidenced in the literature. In addition, sidorenkite is part of a complex paragenesis in the Kola Peninsula. Due to the large variety of minerals, spectroscopy methods can be an important tool in the study of alkaline deposits. The objective of this research is to report the Raman and infrared spectra of sidorenkite and to relate the spectra to the mineral structure.

\section{Experimental}

\section{Samples description and preparation}

The sidorenkite sample studied in this work forms part of the collection of the Geology Department of the Federal University of Ouro Preto, Minas Gerais, Brazil, with sample code SAC-149. The studied sample is from the Umba mine, Alluaiv Mt. Kovdor massif, Kola Peninsula, Russia [11]. The Kola Peninsula is located in the northeastern segment of the Precambrian Baltic Shield. During the Devonian, numerous ultramafic, alkaline and carbonatitic intrusions were emplaced over an area of more than $100,000 \mathrm{~km}^{2}$ which extends from eastern Finland to the eastern Kola Peninsula. These various ultramafic and alkaline silicate rocks found in Kovdor are considered to have been formed from several batches of a carbonated olivine melanephelinite parental magma by a mechanism involving fractional crystallization, magma mixing and/or contamination [12].

The mineral sample was gently crushed and the associated minerals were removed under a stereomicroscope Leica MZ4. The sidorenkite studied in this work occurs as single crystals with prismatic hexagonal form up to $5 \mathrm{~mm}$. Scanning electron microscopy (SEM) in the EDS mode was applied to support the mineral characterization.

\section{Scanning electron microscopy (SEM)}

Experiments and analyses involving electron microscopy were performed in the Center of Microscopy of the Universidade Federal de Minas Gerais, Belo Horizonte, Minas Gerais, Brazil (http:// www.microscopia.ufmg.br).

Sidorenkite crystals were coated with a $5 \mathrm{~nm}$ layer of evaporated carbon. Secondary Electron and Backscattering Electron images were obtained using a JEOL JSM-6360LV equipment. Qualitative and semi-quantitative chemical analyses in the EDS mode were performed with a ThermoNORAN spectrometer model Quest and were applied to support the mineral characterization.

\section{Raman microprobe spectroscopy}

Crystals of sidorenkite were placed on a polished metal surface on the stage of an Olympus BHSM microscope, which is equipped with $10 \times, 20 \times$, and $50 \times$ objectives. The microscope is part of a Renishaw 1000 Raman microscope system, which also includes a monochromator, a filter system and a CCD detector (1024 pixels). The Raman spectra were excited by a Spectra-Physics model 127 He-Ne laser producing highly polarized light at $633 \mathrm{~nm}$ and collected at a nominal resolution of $2 \mathrm{~cm}^{-1}$ and a precision of $\pm 1 \mathrm{~cm}^{-1}$ in the range between 100 and $4000 \mathrm{~cm}^{-1}$. Repeated acquisitions on the crystals using the highest magnification $(50 \times)$ were accumulated to improve the signal to noise ratio of the spectra. Raman Spectra were calibrated using the $520.5 \mathrm{~cm}^{-1}$ line of a silicon wafer. The Raman spectrum of at least 10 crystals was collected to ensure the consistency of the spectra.

\section{Infrared spectroscopy}

Infrared spectra were obtained using a Nicolet Nexus 870 FTIR spectrometer with a smart endurance single bounce diamond ATR cell. Spectra over the $4000-525 \mathrm{~cm}^{-1}$ range were obtained by the co-addition of 128 scans with a resolution of $4 \mathrm{~cm}^{-1}$ and a mirror velocity of $0.6329 \mathrm{~cm} / \mathrm{s}$. Spectra were co-added to improve the signal to noise ratio.

Spectral manipulation such as baseline correction/adjustment and smoothing were performed using the Spectracalc software package GRAMS (Galactic Industries Corporation, NH, USA). Band component analysis was undertaken using the Jandel 'Peakfit' software package that enabled the type of fitting function to be selected and allows specific parameters to be fixed or varied accordingly. Band fitting was done using a Lorentzian-Gaussian cross-product function with the minimum number of component bands used for the fitting process. The Gaussian-Lorentzian ratio was maintained at values greater than 0.7 and fitting was undertaken until reproducible results were obtained with squared correlations of $r^{2}$ greater than 0.995 .

\section{Results and discussion}

\section{Chemical characterization}

The SEM image of sidorenkite sample studied in this work is given in Supplementary information and is given as Fig. S1. The sample corresponds to a cleavage fragment up to $4.0 \mathrm{~mm}$. Qualitative chemical analysis shows a homogeneous phase, composed by $\mathrm{P}, \mathrm{Mn}, \mathrm{Na}$ and C. Small amount of Fe was also observed and occur in substitution to $\mathrm{Mn}$ (Fig. 1). Traces of fluorine were also observed.

\section{Spectroscopy}

Spectroscopy of carbonate anion in solids

Nakamoto et al. first published and tabulated the selection rules for unidenate and bidentate anions including the carbonate anion [13]. The free ion, $\mathrm{CO}_{3}^{2-}$ with $D_{3 h}$ symmetry exhibits four normal

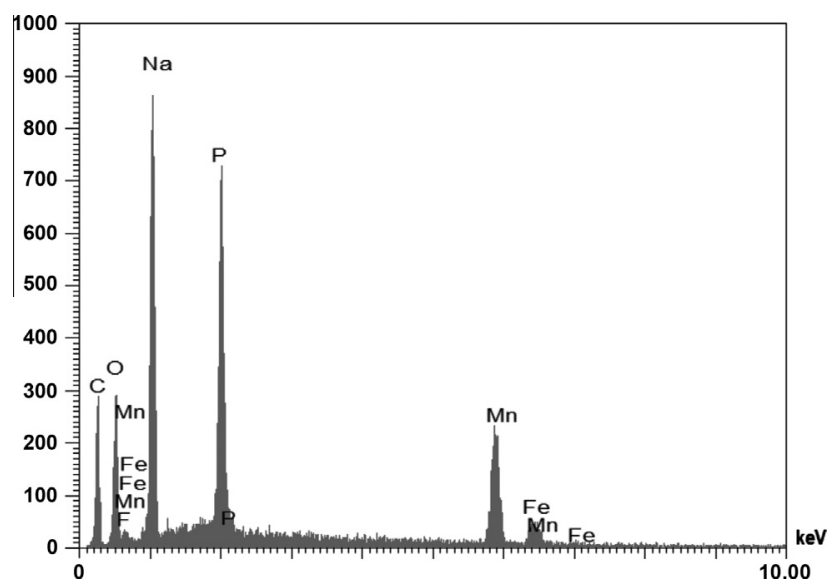

Fig. 1. EDS spectra of sidorenkite. 

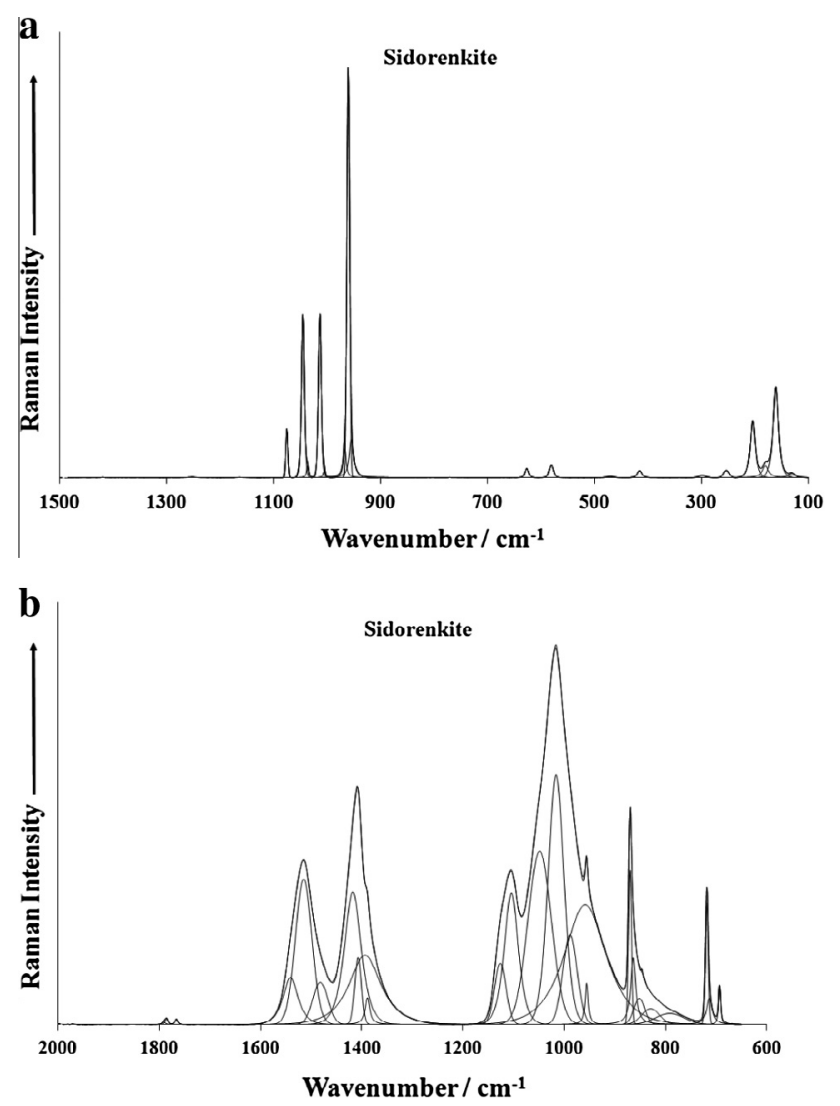

Fig. 2. (a) Raman spectrum of sidorenkite (upper spectrum) over the 100$1500 \mathrm{~cm}^{-1}$ spectral range. (b) Infrared spectrum of sidorenkite (lower spectrum) over the $600-2000 \mathrm{~cm}^{-1}$ spectral range.

vibrational modes; a symmetric stretching vibration $\left(v_{1}\right)$, an outof-plane bend $\left(v_{2}\right)$, a doubly degenerate asymmetric stretch $\left(v_{3}\right)$ and another doubly degenerate bending mode $\left(v_{4}\right)$. The symmetries of these modes are $A_{1}^{\prime}(R)+A_{2}^{\prime \prime}(I R)+E^{\prime}(R, I R)+E^{\prime \prime}(R, I R)$ and occur at $1063,879,1415$ and $680 \mathrm{~cm}^{-1}$ respectively. Generally, strong Raman modes appear around $1100 \mathrm{~cm}^{-1}$ due to the symmetric stretching vibration $\left(v_{1}\right)$, of the carbonate groups, while intense IR and weak Raman peaks near $1400 \mathrm{~cm}^{-1}$ are due to the antisymmetric stretching mode $\left(v_{3}\right)$. Infrared modes near $800 \mathrm{~cm}^{-1}$ are derived from the out-of-plane bend $\left(v_{2}\right)$. Infrared and Raman modes around $700 \mathrm{~cm}^{-1}$ region are due to the in-plane bending mode $\left(v_{4}\right)$. This mode is doubly degenerate for undistorted $\mathrm{CO}_{3}^{2-}$ groups [13]. As the carbonate groups become distorted from regular planar symmetry, this mode splits into two components [13]. Infrared and Raman spectroscopy provide sensitive test for structural distortion of $\mathrm{CO}_{3}^{2}$.

\section{Vibrational spectroscopy}

The Raman spectrum of sidorenkite over the $100-1500 \mathrm{~cm}^{-1}$ spectral range is shown in Fig. 2a. The infrared spectrum of sidorenkite over the $600-2000 \mathrm{~cm}^{-1}$ spectral range is shown in Fig. 2b. These figures display the position and relative intensity of the Raman and infrared bands of sidorenkite. The Raman or infrared spectrum may be subdivided into subsections based upon the type of vibration being studied.

The Raman spectrum of sidorenkite over the $900-1100 \mathrm{~cm}^{-1}$ is reported in Fig. 3a. This spectrum is a very 'clean' spectrum with quite sharp Raman bands. This spectral region is where the carbonate and phosphate stretching modes are to be identified. The sharp Raman band at $959 \mathrm{~cm}^{-1}$ with two low intensity shoulders at 953 and $966 \mathrm{~cm}^{-1}$ is assigned to the $\mathrm{PO}_{4}^{3-} v_{1}$ symmetric stretching
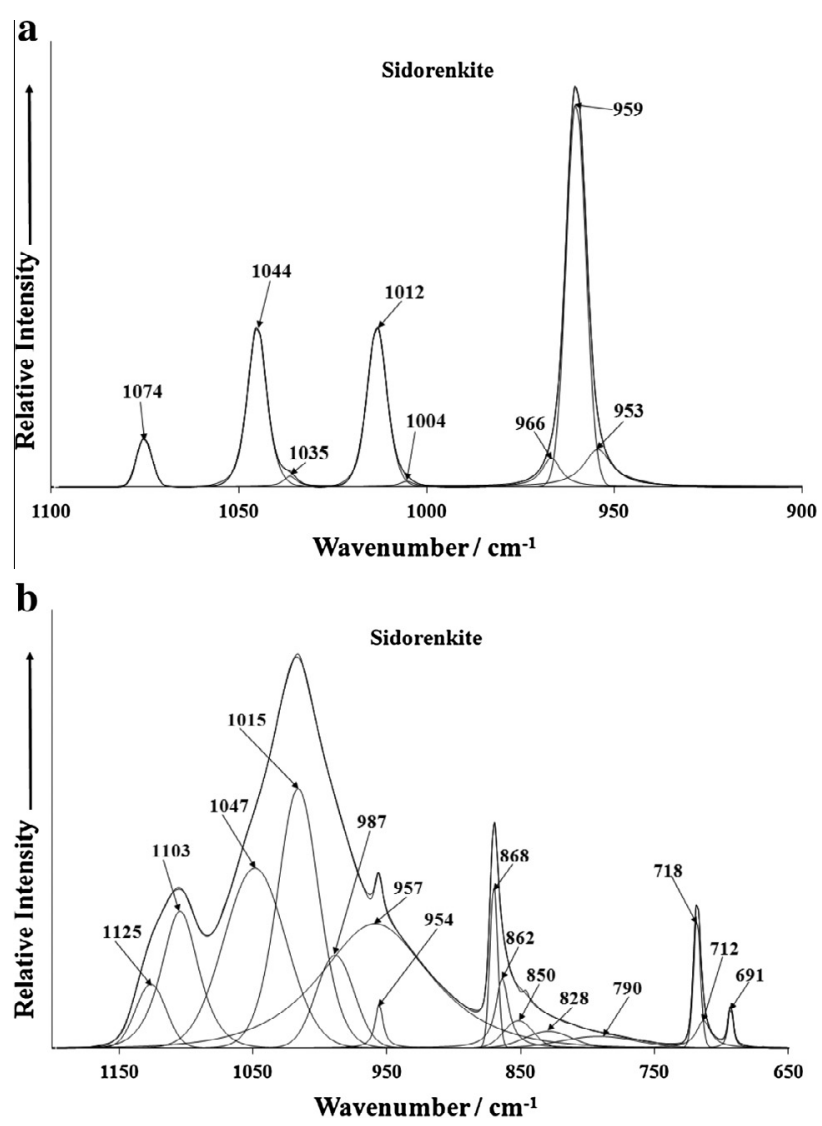

Fig. 3. (a) Raman spectrum of sidorenkite (upper spectrum) in the $900-1100 \mathrm{~cm}^{-1}$ spectral range. (b) Infrared spectrum of sidorenkite (lower spectrum) in the 650$1200 \mathrm{~cm}^{-1}$ spectral range.

mode. The Raman band at $1012 \mathrm{~cm}^{-1}$ with a very low intensity shoulder band at $1004 \mathrm{~cm}^{-1}$ is identified as the $v_{3}$ antisymmetric stretching mode of the phosphate units. The Raman band at $1044 \mathrm{~cm}^{-1}$ with a shoulder at $1035 \mathrm{~cm}^{-1}$ is attributed to the $\mathrm{CO}_{3}^{2-} v_{1}$ symmetric stretching mode and the corresponding $\mathrm{CO}_{3}^{2-}$ $v_{3}$ antisymmetric stretching vibration is noted at $1074 \mathrm{~cm}^{-1}$. It is noted that these bands are observed for the mineral burkeite which is also a anhydrous carbonate mineral at 1062 and $1102 \mathrm{~cm}^{-1}[14]$.

The infrared spectrum over the $650-1200 \mathrm{~cm}^{-1}$ spectral range is illustrated in Fig. 3b. The infrared spectrum when compared with the Raman spectrum is quite broad. Nevertheless, infrared bands may be resolved. The feature at $957 \mathrm{~cm}^{-1}$ is the infrared vibration of the $\mathrm{PO}_{4}^{3-} v_{1}$ symmetric stretching mode. The infrared band at $1015 \mathrm{~cm}^{-1}$ is ascribed to the $\mathrm{PO}_{4}^{3-} v_{3}$ antisymmetric stretching mode. The infrared feature at $1047 \mathrm{~cm}^{-1}$ which is in the envelope of the $1015 \mathrm{~cm}^{-1}$ band is attributed to the $\mathrm{CO}_{3}^{2-} v_{1}$ symmetric stretching mode. The infrared band at $1103 \mathrm{~cm}^{-1}$ with a shoulder band at $1125 \mathrm{~cm}^{-1}$ are assigned to the $\mathrm{CO}_{3}^{2-} \mathrm{v}_{3}$ antisymmetric stretching mode. The infrared bands between 650 and $870 \mathrm{~cm}^{-1}$ are related to the carbonate and phosphate bending modes (and are discussed later).

The infrared spectrum of sidorenkite over the $1200-1700 \mathrm{~cm}^{-1}$ spectral range and over the $1525-1200 \mathrm{~cm}^{-1}$ spectral range are reported in Fig. 4a and b respectively. A series of overlapping bands are noted in this spectral region. Infrared bands are resolved at 1387, 1392, 1406, 1416, 1480, 1513 and $1539 \mathrm{~cm}^{-1}$. These bands are attributed to the $\mathrm{CO}_{3}^{2-} \mathrm{v}_{3}$ antisymmetric stretching mode. Infrared bands are observed at 1765 and $1784 \mathrm{~cm}^{-1}$. It is not certain as to the assignment of these bands but they may be due to overtones or combination bands. 

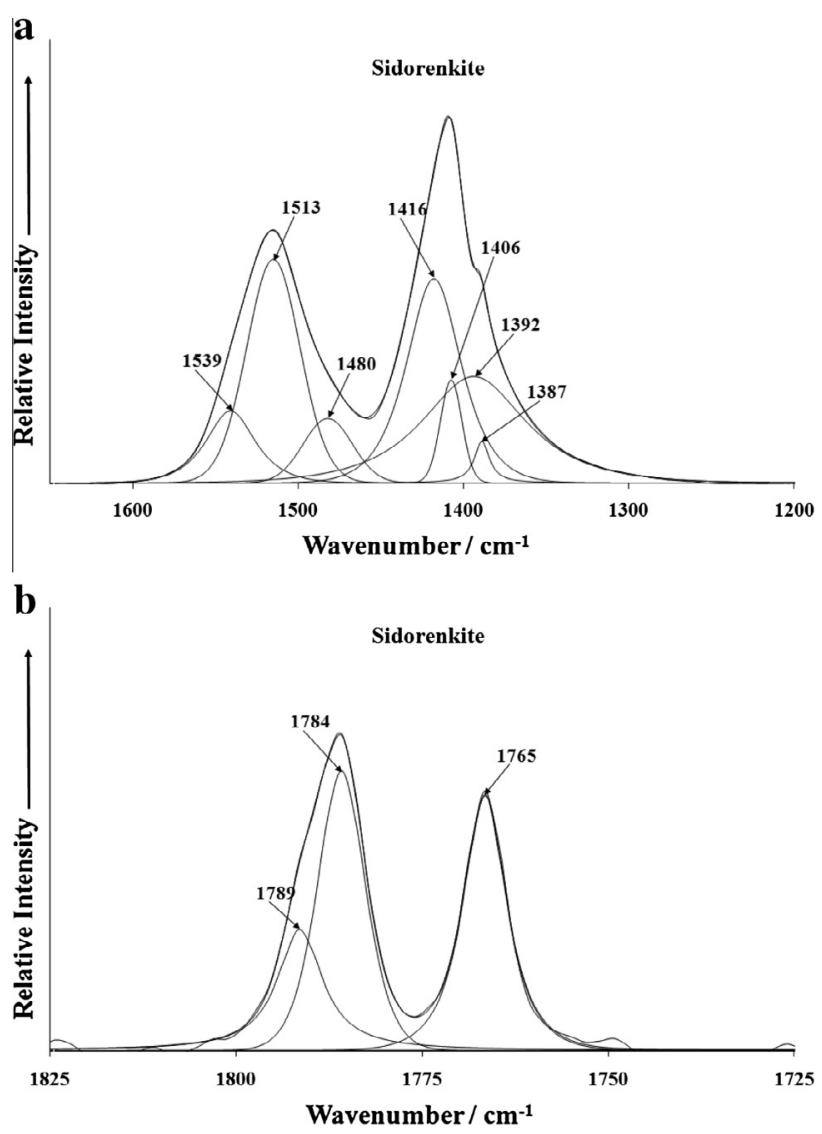

Fig. 4. (a) Infrared spectrum of sidorenkite (lower spectrum) in the 1200$1700 \mathrm{~cm}^{-1}$ spectral range. (b) Infrared spectrum of sidorenkite (lower spectrum) in the $1725-1825 \mathrm{~cm}^{-1}$ spectral range.

The Raman spectrum of sidorenkite over the $350-700 \mathrm{~cm}^{-1}$ and $100-350 \mathrm{~cm}^{-1}$ spectral ranges are displayed in Fig. 5. Infrared modes near $800 \mathrm{~cm}^{-1}$ are derived from the out-of-plane bend $\left(v_{2}\right)$. Infrared and Raman modes around $700 \mathrm{~cm}^{-1}$ region are due to the in-plane bending mode $\left(v_{4}\right)$. This mode is doubly degenerate for undistorted $\mathrm{CO}_{3}^{2-}$ groups. As the carbonate groups become distorted from regular planar symmetry, this mode splits into two components. Infrared and Raman spectroscopy provide sensitive test for structural distortion of $\mathrm{CO}_{3}^{2-}$. It is noted that no Raman bands at around $800 \mathrm{~cm}^{-1}$ for sidorenkite were observed. The infrared spectrum of sidorenkite (Fig. $3 \mathrm{~b}$ ) shows a quite intense band at $868 \mathrm{~cm}^{-1}$ with other resolved component bands at 850, 862 and $868 \mathrm{~cm}^{-1}$. These bands are ascribed to the $\mathrm{CO}_{3}^{2-}$ out-of-plane bend $\left(v_{2}\right)$ bending mode. This infrared spectrum also shows bands at 691, 712 and $718 \mathrm{~cm}^{-1}$ and are assigned to the $\mathrm{CO}_{3}^{2-} \mathrm{v}_{4}$ in plane bending modes. The Raman band at $579 \mathrm{~cm}^{-1}$ is attributed to the $v_{4}$ out of plane bending modes of the $\mathrm{PO}_{4}^{3-}$ units. The Raman bands at 414 and $469 \mathrm{~cm}^{-1}$ are assigned to the $v_{2} \mathrm{PO}_{4}^{3-}$ bending mode. Strong Raman bands are noted in the far low wavenumber region at 159 , $202 \mathrm{~cm}^{-1}$ with low intensity bands at 129, 179, 252 and $297 \mathrm{~cm}^{-1}$ are assigned to lattice modes.

\section{Conclusions}

Raman spectroscopy combined with infrared spectroscopy has been used to study the mineral sidorenkite, a mineral which is found in hyperagpaitic pegmatites in a differentiated alkalic massif (Mt. Alluaiv, Kola Peninsula, Russia). The mineral may be readily determined using vibrational spectroscopy. However, Raman spectroscopy proved more useful for the analysis of sidorenkite, no
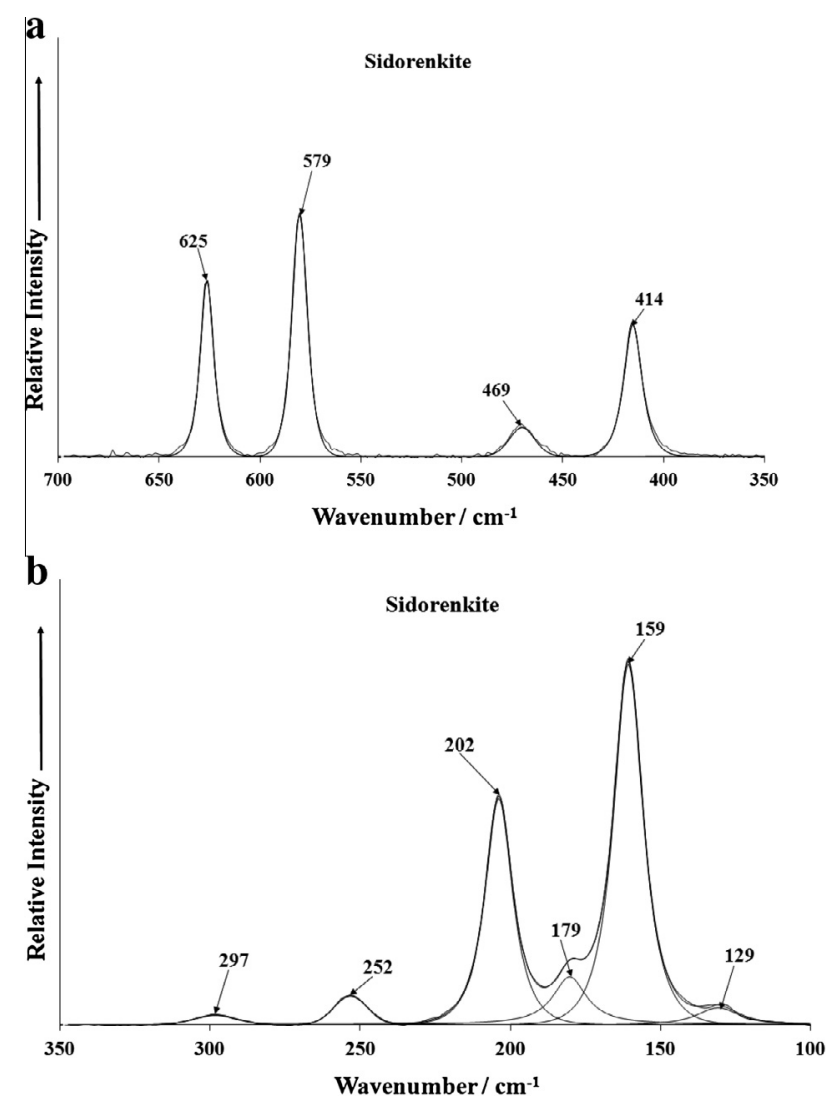

Fig. 5. (a) Raman spectrum of sidorenkite (upper spectrum) in the $350-700 \mathrm{~cm}^{-1}$ spectral range. (b) Raman spectrum of sidorenkite (lower spectrum) in the 100$350 \mathrm{~cm}^{-1}$ spectral range.

doubt because of the smaller spot size, being the order of $1 \mu \mathrm{m}$ as compared with infrared spectroscopy where the spot size is at best around $25 \mu \mathrm{m}$.

\section{Acknowledgements}

The financial and infra-structure support of the Discipline of Nanotechnology and Molecular Science, Science and Engineering Faculty of the Queensland University of Technology, is gratefully acknowledged. The Australian Research Council (ARC) is thanked for funding the instrumentation. The authors would like to acknowledge the Center of Microscopy at the Universidade Federal de Minas Gerais (http://www.microscopia.ufmg.br) for providing the equipment and technical support for experiments involving electron microscopy.

\section{Appendix A. Supplementary material}

Supplementary data associated with this article can be found, in the online version, at http://dx.doi.org/10.1016/j.saa.2014.08.029.

\section{References}

[1] A.P. Khomyakov, E.I. Semenov, M.E. Kazakova, N.G. Shumyatskaya, Zap. Vsesoyuznogo Min. 108 (1979) 56-59.

[2] A.P. Khomyakov, A.V. Bykova, A.P. Shlikhter, Zap. Vsesoyuznogo Min. 109 (1980) 592-594.

[3] E.I. Semenov, A.P. Khomyakov, Sovetskaya Geol. (1986) 97-103.

[4] T.A. Kurova, N.G. Shumyatskaya, A.A. Voronkov, Y.A. Pyatenko, Min. Zh. 2 (1980) 65-70.

[5] T.A. Kurova, N.G. Shumyatskaya, A.A. Voronkov, Y.A. Pyatenko, Dok. Akad. Nauk SSSR 251 (1980) 605-607. 
[6] T. Chinh Thi Le, T.N. Nadezhina, E.A. Pobedimskaya, A.P. Khomyakov, Min. Zh. 6 (1984) 79-84.

[7] H. Chen, Q. Hao, O. Zivkovic, G. Hautier, L.-S. Du, Y. Tang, Y.-Y. Hu, X. Ma, C.P. Grey, G. Ceder, Chem. Mat. 25 (2013) 2777-2786.

[8] A.P. Khomjakov, L.I. Polezhaeva, E.V. Sokolova, Zap. Vsesoyuznogo Min. 123 (1994) 107-111.

[9] A.P. Khomyakov, A.V. Bykova, Y.A. Malinovskii, Zap. Vsesoyuznogo Min. 109 (1980) 476-479.

[10] A.P. Khomyakov, Y.A. Malinovskii, S.M. Sandomirskaya, Zap. Vsesoyuznogo Min. 110 (1981) 600-603.
[11] P.M. Kartashov, G. Ferraris, S.V. Soboleva, N.V. Chukanov, Can. Min. 44 (2006) 1331-1339.

[12] M.J. Lee, J.I. Lee, S.D. Hur, Y. Kim, J. Moutte, E. Balaganskaya, Lithos 91 (2006) 250

[13] K. Nakamoto, J. Fujita, S. Tanaka, M. Kobayashi, J. Amer. Chem. Soc. 79 (1957) 4904-4908.

[14] A. Lopez, R.L. Frost, Y. Xi, R. Scholz, Spectrosc. Lett. (Ahead of Print). 